\title{
The effects of local ischemic preconditioning and topical hypothermia in renal ischemia/reperfusion injury in rats ${ }^{1}$
}

Guilherme Behrend Ribeiro', Emanuel Burck dos Santos", Silvia Regina Bona"', Pedro Guilherme Schaefer'v, Tuane Alves Garcez ${ }^{\mathrm{V}}$, Eduardo Brasil RabolinivI', Guilherme Pereira Smaniottovı, Norma Possa Marronivil, Carlos Otávio Corso vilI

'Fellow Master degree, Postgraduate Program in Medicine: Surgical Sciences, Universidade Federal do Rio Grande do Sul (UFRGS), Porto Alegre-RS, Brazil. Conception and design of the study; technical procedures; acquisition, interpretation and analysis of data; manuscript writing.

"MSc, PhD, Department of Urology, Hospital de Clínicas de Porto Alegre (HCPA), Brazil. Conception and design of the study, critical revision.

I'PhD, Laboratory of Experimental Gastroenterology and Hepatology, HCPA, Brazil. Acquisition and interpretation of data, technical procedures.

IVMD, Department of Pathology, HCPA, Porto Alegre-RS, Brazil. Histopathological examinations, acquisition of data.

${ }^{\vee}$ MSc, Animal Experimentation Unit, HCPA, Porto Alegre-RS, Brazil. Technical procedures.

${ }^{V}$ 'Graduate student, School of Medicine, UFRGS, Porto Alegre-RS, Brazil. Acquisition of data, technical procedures.

VIIMSc, Full Professor, Physiologist, Laboratory of Experimental Gastroenterology and Hepatology, UFRGS, Porto AlegreRS, and Laboratory of Oxidative Stress and Antioxidants, Universidade Luterana do Brasil (ULBRA), Canoas-RS, Brazil. Acquisition and interpretation of data, technical procedures.

VIIIMSc, Associate Professor of Surgery, Digestive Surgery Unit, HCPA, and Department of Surgery, UFRGS, Porto Alegre$\mathrm{RS}$, Brazil. Conception and design of the study, interpretation of data, manuscript writing, critical revision, final approval.

\section{Abstract}

Purpose: Topical hypothermia and local ischemic preconditioning have been shown to reduce renal ischemia-reperfusion (I/R) injury individually. We examined whether combination of both strategies lessens renal I/R injury.

Methods: Post right nephrectomy, 40 male Wistar rats were randomly assigned to five experimental protocols performed in the left kidney: topical hypothermia without ischemia $(T H)$, warm ischemia (IR), ischemic preconditioning followed by warm ischemia (IPC+IR), cold ischemia ( $T H+I R)$, and ischemic preconditioning followed by cold ischemia (IPC+TH+IR). Eight randomly assigned right kidneys constituted the control group. After $240 \mathrm{~min}$ of reperfusion, the left kidney was retrieved to evaluate histological changes, lipid peroxidation and antioxidant enzymes activity. Serum was collected to evaluate urea and creatinine.

Results: IPC+TH+IR group revealed no difference to any other group subjected to ischemia in relation to histological changes, lipid peroxidation and antioxidant enzymes activity. Creatinine was lower in IPC+TH+IR group compared with IPC+IR, but showed no difference compared to $\mathrm{TH}+\mathrm{IR}$ group.

Conclusions: Combination of local ischemic preconditioning (IPC) and topical hypothermia conferred no protection in renal I/R injury. Moreover, local IPC solely followed by warm ischemia impaired renal function more than warm ischemia alone.

Key words: Ischemic Preconditioning. Hypothermia. Reperfusion Injury. Oxidative Stress. Kidney. Rats. 


\section{Introduction}

Ischemia-reperfusion (I/R) injury underlies much of the tissue damage that occurs in stroke and myocardial infarction, two of the most common clinical I/R syndromes, and it also plays a part in damage to other organs following ischemia ${ }^{1}$. In partial nephrectomies and renal transplants, the kidney is exposed to variable periods of warm and cold ischemia. Cell injury and death follow interruption of the blood supply to the kidney, and reperfusion is mandatory to salvage the tissue. However, despite reperfusion being an integral part of the healing process, it also contributes to the exacerbation of tissue injury and a profound inflammatory response, called 'reperfusion injury'. This entire pathophysiology has been described as the I/R injury ${ }^{2}$.

The kidney is comprised of heterogeneous cell populations that function in concert to perform a number of tightly controlled and complex processes. Ischemia leads to molecular changes in the vasculature and interstitium of the kidney, and reperfusion gives rise to an acute inflammatory response. Together, these events induce acute kidney injury, resulting in the disruption of renal function and a reduction of glomerular filtration rate $^{3}$. In kidney transplantation, the degree of $I / R$ injury determines the speed of recovery of organ function in the short-term ${ }^{4}$ and may modulate organ rejection in the longterm by priming the immune system early after transplantation ${ }^{5,6}$. Therefore, reduction in $\mathrm{I} / \mathrm{R}$ injury has the potential to improve the outcome of kidney (and other organs) transplantation, in both the short and long term ${ }^{7}$.

Strategies to limit clinical $I / R$ injury have mainly focused on timely reperfusion and hypothermia ${ }^{8,9}$. Topical hypothermia (TH) with pulsatile perfusion or single flushing of a preservation solution has been the mainstay of kidney storage for transplantation ${ }^{10}$. However, the number of transplants that fail each year and increasing waiting lists highlight that new strategies are needed to enhance kidney tolerance to $\mathrm{I} / \mathrm{R}$ injury ${ }^{11}$. One such strategy is ischemic preconditioning (IPC).

IPC involves application of a brief episode of ischemia and reperfusion (conditioning stimulus), resulting in tissue tolerance to subsequent $\mathrm{I} / \mathrm{R}$ injury ${ }^{12}$. The conditioning stimulus has been shown to be effective when applied either to the target organ itself (local IPC) or to a remote organ or tissue (remote IPC) ${ }^{13}$. Currently, many of the complex signal-transduction pathways underlying ischemic preconditioning have been clarified ${ }^{14}$. One of the mechanisms seems to be the reduction of oxidative stress through an increase in antioxidant enzymes ${ }^{15-17}$.

Given the experimental knowledge that TH and local IPC are efficient strategies to reduce renal $I / R$ injury, it would be important to know if a combination of both strategies could have synergistic protective effects. We therefore sought to study the effects of local IPC combined with TH on renal I/R injury, particularly on the extent of histological changes, oxidative stress damage, antioxidant enzymes activity, and biochemical functional parameters.

\section{Methods}

The study was approved by the Hospital de Clínicas de Porto Alegre (HCPA). Animals Research Ethics Committee (case 140091) in accordance with the International Guiding Principles for Biomedical Research Involving Animals, published by the Council for International Organizations of Medical Sciences (CIOMS), as well as with the Brazilian law on scientific use of animals (Law 11794/2008).

\section{Animals and experimental design}

Adult male Wistar rats weighing between 235 and $405 \mathrm{~g}$ (7-11 weeks old) were 
housed in the Animal Experimentation Unit of Hospital de Clínicas de Porto Alegre in groups of four in separate cages at room temperature $\left(22 \pm 2^{\circ} \mathrm{C}\right)$ with a 12-hour light/dark cycle and free access to water and rat chow. In a prospective design, rats were randomly allocated to five experimental groups (Figure 1). Group $1(\mathrm{TH}, \mathrm{n}=8)$ rats underwent left kidney $\mathrm{TH}$ at $4^{\circ} \mathrm{C}$ for $40 \mathrm{~min}$ without ischemia. This group was designed to appreciate if deep hypothermia could cause any damage. Group 2 (IR, $n=8)$ rats underwent left kidney warm ischemia for $40 \mathrm{~min}$ and subsequent
$4 \mathrm{~h}$ reperfusion. Group $3(\mathrm{IPC}+\mathrm{IR}, \mathrm{n}=8)$ rats underwent left kidney IPC, consisting of 15 min of warm ischemia and 10 min of reperfusion, followed by warm ischemia for $40 \mathrm{~min}$ and subsequent $4 \mathrm{~h}$ reperfusion. Group $4(\mathrm{TH}+\mathrm{IR}$, $\mathrm{n}=8$ ) rats underwent left kidney cold ischemia for $40 \mathrm{~min}$ and subsequent $4 \mathrm{~h}$ reperfusion. Group 5 (IPC+TH+IR, $n=8)$ rats underwent left kidney IPC followed by cold ischemia for 40 min and subsequent $4 \mathrm{~h}$ reperfusion. Right nephrectomy was performed in all rats before any intervention. Eight randomly assigned right kidneys constituted the control group $(n=8)$.

\begin{tabular}{|c|c|c|c|c|}
\hline Group 1 (TH) & $\mathrm{C}$ & $40^{\prime}$ & & $240^{\prime} r$ \\
\hline Group 2 (IR) & $\mathrm{C}$ & $40^{\prime} \mathrm{i}$ & & $240^{\prime} r$ \\
\hline Group 3 (IPC+IR) & $\mathrm{C}$ & \begin{tabular}{l|l|}
$15^{\prime} \mathrm{i}$ & $10^{\prime} \mathrm{r}$ \\
\end{tabular} & $40^{\prime} \mathrm{i}$ & $240^{\prime} r$ \\
\hline Group 4 (TH+IR) & $\mathrm{C}$ & $\begin{array}{l}\text { IPC } \\
40^{\prime} i \\
\end{array}$ & & $240^{\prime} r$ \\
\hline Group 5 (IPC+TH+IR) & $\mathrm{C}$ & \begin{tabular}{l|l|}
$15^{\prime} \mathrm{i}$ & $10^{\prime} \mathrm{r}$ \\
\end{tabular} & $40^{\prime} \mathrm{i}$ & $240^{\prime} r$ \\
\hline
\end{tabular}

Figure 1 - Experimental protocols.

" $C$ " indicates retrieval of right kidney for Group 0 (control). " $i$ " indicates ischemia and " $r$ " indicates reperfusion. Blue color indicates topical hypothermia. TH: topical hypothermia without ischemia; IR: ischemia and reperfusion; IPC+IR: ischemic preconditioning followed by ischemia and reperfusion; TH+IR: topical hypothermia with ischemia and reperfusion; IPC+TH+IR: ischemic preconditioning followed by topical hypothermia with ischemia and reperfusion.

After weighing, the animals underwent inhalation general anesthesia induction with isoflurane vaporizer at 3-5\%, administrated through campanula. Blood from retro-ocular plexus was collected. Then, animals were placed on a warm surgical table in supine position and rear paw reflexes were tested to ensure that adequate anesthesia was achieved. Oxygen at $1 \mathrm{~L} / \mathrm{min}$ and isoflurane at $2-3 \%$ were used for maintenance. A common electronic rectal thermometer (Termomed 1.0, Incoterm, Porto Alegre, Brazil) was used for assessing systemic temperature. If needed, a heating lamp was used to maintain the systemic temperature between $35.5^{\circ} \mathrm{C}$ and $37.5^{\circ} \mathrm{C}$. Before the abdominal incision, bupivacaine $0.5 \%$ was injected in the abdominal wall to ensure pain control during and after the procedure. A longitudinal median incision was made on the abdomen and surgical retractors were applied. Right nephrectomy was performed. Half of the right kidney was put in $10 \%$ formalin and the other half frozen and stored at $-80^{\circ} \mathrm{C}$. Then one of the five protocols described was applied to the left kidney. To induce ischemia, the renal pedicle was clamped with an atraumatic microvascular cranial surgery clip (Medicon, Tuttlingen, Germany). Cortical left kidney temperature was assessed with an intraparenchymal probe connected to a specific 
thermometer (BAT 12, IITC Life Science, W. Hills, CA, USA). In groups exposed to $\mathrm{TH}$ ( $\mathrm{TH}, \mathrm{TH}+\mathrm{IR}$ and IPC+TH+IR groups), the left kidney targettemperature $\left(4^{\circ} \mathrm{C}\right)$ was achieved with ice slush of saline solution. To avoid systemic hypothermia, a suction system was installed to remove the cold saline solution and the left kidney was isolated from the rest of the abdominal cavity through the application of a specially designed device made of polystyrene and latex (Figure 2). After $40 \mathrm{~min}$ of $\mathrm{TH}$ and/or ischemia, renal pedicle was unclamped and abdominal wall was closed. Animals were moved to a new warm cage with water, but without food. After $4 \mathrm{~h}$ of reperfusion, they were moved again from the cage to the surgical table. Inhalation general anesthesia was used as before. The abdominal wall sutures were removed and left nephrectomy was accomplished. The same procedures performed on the right kidney were carried out for the left one. Blood sample was collected through heart puncture. Cardiectomy was performed to ensure animal death under anesthesia.

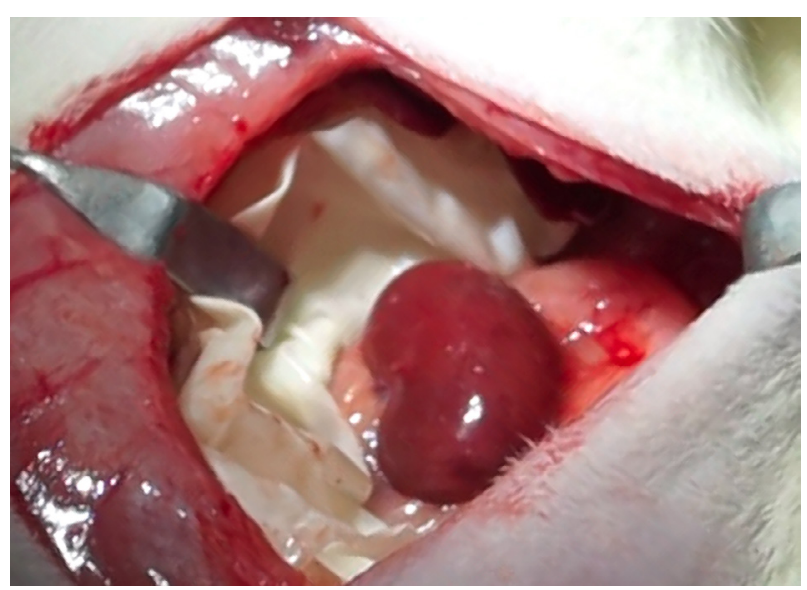

Figure $\mathbf{2}$ - The manufactured device made by sticking half of the bottom part of a polystyrene cup inside a latex glove finger.

\section{Histological changes}

Half of each kidney was fixed in $10 \%$ formalin, embedded in paraffin, sliced, and stained with hematoxylin and eosin (H\&E) and periodic acid-Schiff (PAS) method. The PAS highlights the initial changes seen in acute tubular necrosis. Thus, it is straightforward to see the thinned or absent brush border of proximal tubules. The criteria employed to grade the severity of acute tubular necrosis were the 5-point scale described by Jablonski et al. ${ }^{18}$ with the following grades: 0 , no abnormality; 1 , mitoses and necrosis of individual cells; 2 , necrosis of all cells in adjacent proximal convoluted tubules, with survival of surrounding tubules; 3 , necrosis confined to the distal third of the proximal convoluted tubule with a band of necrosis extending across the inner cortex; 4 , necrosis affecting all three segments of the proximal convoluted tubules. All slices were examined by an experienced renal pathologist, who was blinded to the control and treatment groups.

\section{Kidney homogenate preparation}

Kidneyswere weighedand homogenized for $40 \mathrm{sec}$ in an Ultra-Turrax homogenizer (IKA Works Inc., Wilmington, DE, USA) at $4{ }^{\circ} \mathrm{C}$ in the presence of $1.15 \% \mathrm{KCl}$ ( $9 \mathrm{ml}$ per $\mathrm{g}$ of tissue) and phenyl-methyl-sulfonyl fluoride (PMSF) at a concentration of $100 \mathrm{mM}$ in isopropanol (10 $\mu 1$ per $\mathrm{ml}$ of $\mathrm{KCl}$ ). The homogenate was then centrifuged for $10 \mathrm{~min}$ at 3,000 rpm in a refrigerated centrifuge (SORVALL Super T21; Kendro Laboratory Products, Weaverville, NC, USA). The precipitate was discarded and the supernatant was recovered and frozen at $-80^{\circ} \mathrm{C}$ for subsequent biochemical analysis.

\section{Protein}

Protein concentrations were determined using the Bradford method with bovine albumin as a standard, followed by spectrophotometry at $595 \mathrm{~nm}$. It was used to determine antioxidant enzyme levels. 


\section{Oxidative stress damage}

The amount of oxidative stress damage was evaluated by measuring the levels of F2isoprostanes (F2IP), a reliable biomarker of lipid peroxidation in the tissues, using 8-isoPGF2 $\alpha$ ELISA kit (ADI-900-010, Enzo Life Sciences Inc., Farmingdale, NY, USA) after kidney homogenization.

\section{Antioxidant enzyme activity}

Superoxide dismutase (SOD) activity was determined by the inhibition of the reaction of superoxide-dependent adrenaline auto-oxidation in a spectrophotometer at 480 $\mathrm{nm}$. Results were expressed as USOD/min/mg protein. Catalase (CAT) activity was calculated based on the decomposition of hydrogen peroxide on a spectrophotometer at $240 \mathrm{~nm}$. The results of this procedure were expressed as $\mathrm{pmol} / \mathrm{mg}$ protein.

\section{Biochemical functional parameter analysis}

Levels of serum urea and creatinine $(\mathrm{s} C r)$ at baseline (from the blood collected from the retro-orbital plexus) and at the end of the experiment (from the blood collected from the heart) were estimated using a Roche Cobas 8000 c702 automatic biochemistry apparatus. Biochemical functional parameters were analyzed only with regard to experimental groups because urea and $\mathrm{sCr}$ were estimated from peripheral blood.

\section{Statistics}

Data were analyzed for statistical significance by the application of generalized linear models using SPSS software (SPSS Statistics for Windows, Version 21.0, IBM Corp.,
Armonk, NY, USA). It used the normal model for symmetrical variables and gamma model for asymmetrical variables. Because this involved multiple paired tests, the Bonferroni correction was applied to the significance level of each test. All $P$ values were two-tailed, and a $P$ value of less than 0.05 was considered statistically significant. Data are shown as mean \pm standard error (SE).

\section{- Results}

Weight was not different between groups. Minimum systemic temperature was lower in animals subjected to $\mathrm{TH}(\mathrm{P}<$ 0.001 ), despite all efforts to maintain systemic temperature in the normal range. Nonetheless, the minimum systemic temperatures in these groups were slightly below normal ranges ( $\mathrm{TH}: 36.1 \pm 0.1^{\circ} \mathrm{C}, \mathrm{TH}+\mathrm{IR}: 35.5 \pm 0.3^{\circ} \mathrm{C}$, and IPC+TH+IR: $35.8 \pm 0.3^{\circ} \mathrm{C}$ ). Urea and $\mathrm{sCr}$ were similar across all groups at baseline.

Histological evaluation revealed grades of acute tubular necrosis ranging from 1 to 3 (Figures 3 to 5). Because there was too much overlapping of histological changes between groups, it was not possible to assign a specific grade to any particular group (except for control group, which uniformly exhibited grade 0 pattern). There was no case of grade 4 . Analysis of histological changes showed higher grades of tissue injury in kidneys of animals that underwent warm ischemia (IR and IPC+IR groups) compared with controls and kidneys of animals subjected to topical hypothermia ( $\mathrm{TH}$ and $\mathrm{TH}+\mathrm{IR}$ groups). An exception was the IPC+TH+IR group; when IPC was added to 40 min of cold ischemia, IPC seemed to decrease $\mathrm{TH}$ protection as seen by histological changes attributable to I/R injury (Figure 6). 


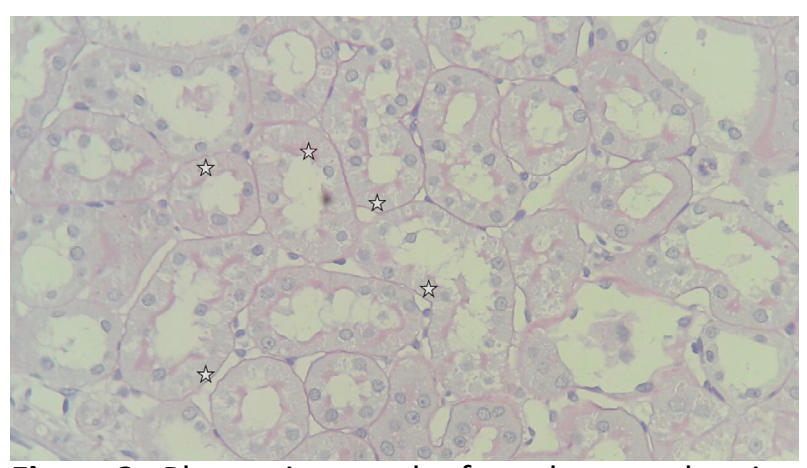

Figure 3 - Photomicrograph of renal cortex showing necrosis of individual cells and mitotic figures in Grade 1 acute tubular necrosis. (PAS x400)

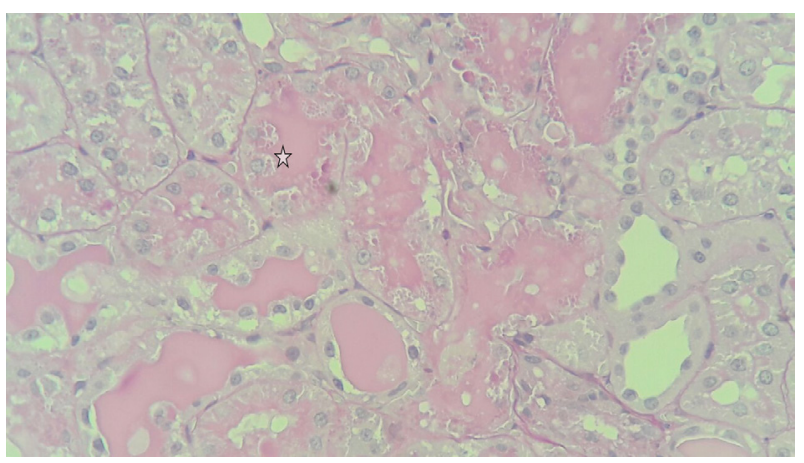

Figure 4 - Photomicrograph of renal cortex showing necrosis of a group of proximal convuluted tubules in Grade 2 acute tubular necrosis. (PAS x400)

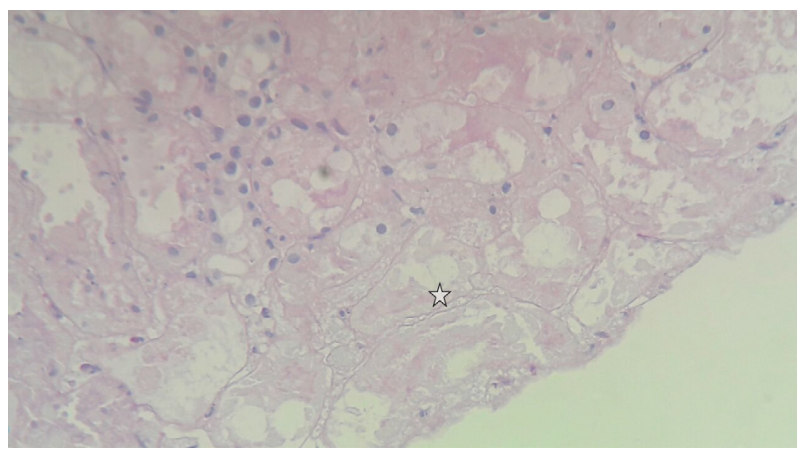

Figure 5 - Photomicrograph of renal cortex showing necrosis of distal third of the proximal convoluted tubules in Grade 3 acute tubular necrosis. (PAS $\mathrm{x} 400$ )

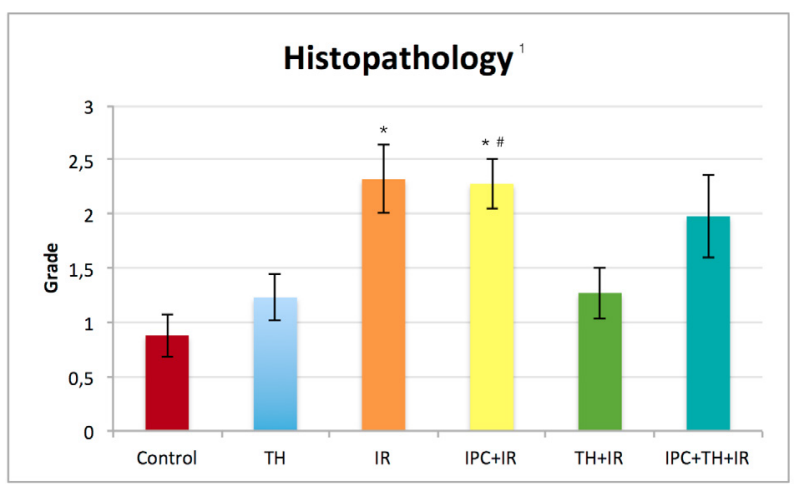

Figure 6 - Grades of histological changes.

${ }^{1}$ Data are expressed as mean $\pm \mathrm{SE}$. Generalized linear models were adjusted to weight, age, and minimum systemic temperature. The Bonferroni correction was applied to the significance level of each test; *Significantly different from Control and TH $(\mathrm{P}<0.05)$; \#Significantly different from $\mathrm{TH}+\mathrm{IR}$ $(P<0.05)$; TH: topical hypothermia without ischemia; IR: ischemia and reperfusion; IPC+IR: ischemic preconditioning followed by ischemia and reperfusion; TH+IR: topical hypothermia with ischemia and reperfusion; IPC+TH+IR: ischemic preconditioning followed by topical hypothermia with ischemia and reperfusion.

Oxidative stress damage, as measured by F2IP tissue assay, was lower in $\mathrm{TH}$ group, compared with $\mathrm{TH}+\mathrm{IR}$ and IPC+TH+IR groups. Most importantly, F2IP tissue levels in all the groups subjected to ischemia (IR, IPC+IR, TH+IR and IPC+TH+IR groups) were not statistically different from those in controls (Figure 7).

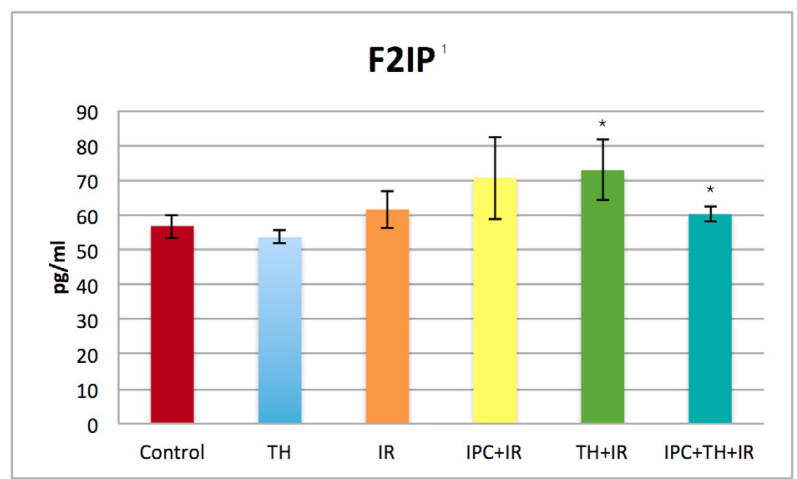

Figure 7 - F2-isoprostanes tissue assay.

${ }^{1}$ Data are expressed as mean $\pm \mathrm{SE}$. Generalized linear models were adjusted to weight, age, and minimum systemic temperature. The Bonferroni correction was applied to the significance level of each test; "Significantly different from TH $(\mathrm{P}<0.05)$; TH: topical hypothermia without ischemia; IR: ischemia and reperfusion; IPC+IR: ischemic preconditioning followed by ischemia and reperfusion; TH+IR: topical hypothermia with ischemia and reperfusion; IPC+TH+IR: ischemic preconditioning followed by topical hypothermia with ischemia and reperfusion. 
Antioxidant enzymes activity results are shown in Table 1. CAT activity was increased in groups subjected to warm ischemia (IR and IPC+IR groups), compared with $\mathrm{TH}+\mathrm{IR}$ group.
When IPC was added to 40 min of cold ischemia (IPC+TH+IR group), CAT activity showed no difference in any group. SOD activity was not statistically different among the groups.

Table 1 - Antioxidant enzymes activity ${ }^{1 .}$

\begin{tabular}{lllllll}
\hline Variables & Control & TH & IR & IPC+IR & TH+IR & IPC+TH+IR \\
\hline CAT (pmol/mg prot) & $64.4 \pm 6.1$ & $60.5 \pm 5.5$ & $81.8 \pm 6.9 *$ & $74.1 \pm 4.0^{*}$ & $47.5 \pm 4.8$ & $59.9 \pm 2.3$ \\
SOD (USOD/min/mg prot) & $9.4 \pm 1.2$ & $7.1 \pm 0.6$ & $8.6 \pm 1.4$ & $7.0 \pm 0.5$ & $8.7 \pm 2.3$ & $6.3 \pm 0.6$ \\
\hline
\end{tabular}

${ }^{1}$ Data are expressed as mean \pm SE. Generalized linear models adjusted to weight, age, and minimum systemic temperature. The Bonferroni correction was applied to the significance level of each test; ${ }^{*}$ Significantly different from $T H+I R(P<0.05)$; TH: topical hypothermia without ischemia; IR: ischemia and reperfusion; IPC+IR: ischemic preconditioning followed by ischemia and reperfusion; TH+IR: topical hypothermia with ischemia and reperfusion; IPC+TH+IR: ischemic preconditioning followed by topical hypothermia with ischemia and reperfusion.

Functional parameters at the end of the experiment revealed a higher urea in IPC+IR group, compared with IR group (Figure 8), and a higher $\mathrm{sCr}$ in IPC+IR group compared to all the other experimental groups (Figure 9).

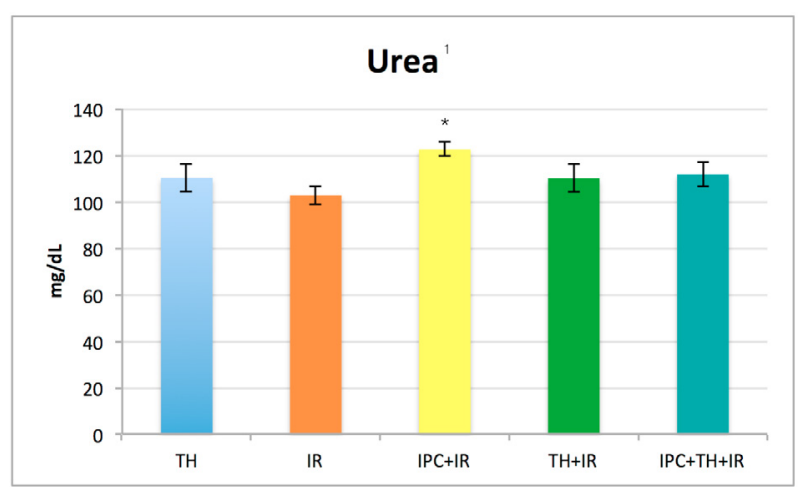

Figure 8 - Serum urea levels.

${ }^{1}$ Data are expressed as mean $\pm \mathrm{SE}$. Generalized linear models were adjusted to weight, age, and minimum systemic temperature. The Bonferroni correction was applied to the significance level of each test. Analysis included only experimental groups because urea was estimated from peripheral blood at the end of the experiment; *Significantly different from IR ( $P<0.05)$; TH: topical hypothermia without ischemia; IR: ischemia and reperfusion; IPC+IR: ischemic preconditioning followed by ischemia and reperfusion; TH+IR: topical hypothermia with ischemia and reperfusion; IPC+TH+IR: ischemic preconditioning followed by topical hypothermia with ischemia and reperfusion.

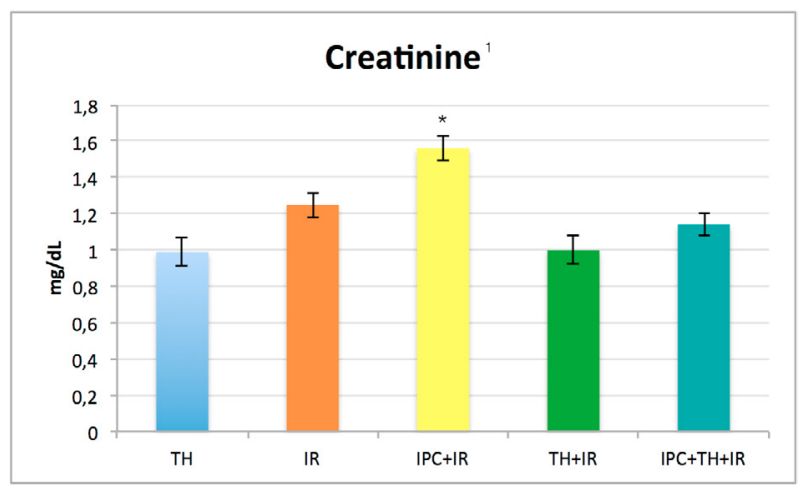

Figure 9 - Serum creatinine levels.

${ }^{1}$ Data are expressed as mean \pm SE. Generalized linear models were adjusted to weight, age, and minimum systemic temperature. The Bonferroni correction was applied to the significance level of each test. Analysis included only experimental groups because $\mathrm{sCr}$ was estimated from peripheral blood at the end of the experiment; "Significantly different from all other groups $(P<0.05)$; TH: topical hypothermia without ischemia; IR: ischemia and reperfusion; IPC+IR: ischemic preconditioning followed by ischemia and reperfusion; $\mathbf{T H}+\mathbf{I R}$ : topical hypothermia with ischemia and reperfusion; IPC+TH+IR: ischemic preconditioning followed by topical hypothermia with ischemia and reperfusion.

\section{Discussion}

Although several studies have tried to evaluate the effects of ischemic preconditioning on renal I/R injury, none of them investigated if local ischemic preconditioning had 
synergistic protective effect when combined with topical hypothermia during prolonged ischemia ${ }^{13}$. Torras et al. ${ }^{19}$ published functional and histological results of local ischemic preconditioning in kidneys flushed with EuroCollins solution and cold stored for 5 hours before transplantation. They showed that ischemic preconditioning before cold storage resulted in lower $\mathrm{sCr}$ and acute tubular necrosis following transplantation. Considering that topical hypothermia is an important surgical tool not only for transplantation, but also for other clinical scenarios such as partial nephrectomy, the present study was designed to evaluate if local ischemic preconditioning and topical hypothermia merge protective effects on $\mathrm{I} / \mathrm{R}$ injury following $40 \mathrm{~min}$ of ischemia in an acute experiment $(4 \mathrm{~h}$ of reperfusion) using histological changes as the main outcome. Tissue lipid peroxidation and antioxidant enzymes activity were evaluated because of scarcity of data regarding the effect of ischemic preconditioning on them, despite the relevance of oxidative stress to I/R injury ${ }^{20}$. Moreover, urea and $\mathrm{s} C r$ were tested in order to look for functional evidence of additive effect of ischemic preconditioning with topical hypothermia.

Right nephrectomy was performed before any intervention was performed because recovery of an ischemically damaged kidney is affected by the presence of a healthy kidney ${ }^{21}$. We showed that topical hypothermia by itself did not cause histological changes, oxidative stress damage, or changes in antioxidant enzymes activity compared to controls. Regarding histological changes in groups subjected to ischemia, ischemic preconditioning unexpectedly increased acute tubular necrosis, while topical hypothermia showed a trend towards decreasing it. The combination of ischemic preconditioning to topical hypothermia was neither beneficial nor detrimental, compared to ischemia alone. Some previously published studies that evaluated histological damage using a comparable 5-point scale showed significantly lower acute tubular necrosis when local ischemic preconditioning was performed before prolonged ischemia, but not all studies have reported positive findings. A recent metaanalysis collectively evaluating the effects of local and remote ischemic preconditioning on histological changes indicates that ischemic preconditioning is beneficial ${ }^{13}$.

We found increased antioxidant CAT activity in warm ischemia groups (IR and IPC+IR), compared with TH+IR group. Ischemic preconditioning combined to cold ischemia (IPC+TH+IPC group) resulted in similar CAT activity, compared to TH+IR group. The increase in CAT activity observed in IR group was also previously observed in kidneys exposed to similar conditions of I/R injury ${ }^{17}$. Other studies with different periods of warm ischemia and reperfusion before kidney tissue harvesting reported conflicting results ${ }^{22-26}$. In essence, longer periods of ischemia consistently led to loss of CAT activity ${ }^{22-25}$. Perhaps the increase in CAT activity in our model occurred because ischemia and reperfusion periods were short, inducing slight oxidative stress that triggered an increase in CAT activity in the first few hours before its inactivation.

Our evaluation of F2IP levels did not reach statistical significance between groups in which kidneys experienced ischemia. As expected, topical hypothermia at $4^{\circ} \mathrm{C}$ without ischemia proved to cause no oxidative damage. Using another marker for lipid peroxidation, thiobarbituric acid reactive substances (TBARS), Dobashi et al. ${ }^{22}$ showed no increase in its levels with $30 \mathrm{~min}$ of warm ischemia. Nonetheless, ischemia for 60 or 90 min consistently increased lipid peroxidation. SOD activity was similar among our groups. Although it also has conflicting results in the literature, the variation patterns are much like those of $\mathrm{CAT}^{22-26}$. 
Regarding kidney function parameters, our experiment protocol showed that IPC impaired kidney function, compared to all other groups, as demonstrated by the significant increase in urea and $\mathrm{sCr}$ levels. In contrast, when IPC was combined to topical hypothermia, it looks like the functional damage caused by IPC was mitigated. The only published meta-analysis on this subject reports that ischemic preconditioning preserves renal function ${ }^{13}$. Nevertheless, it should be pointed out that the results of this meta-analysis are possibly inaccurate because of publication bias. Wever et al. ${ }^{13}$ stated that visual analysis of funnel plots revealed that small, negative studies appeared to be underrepresented, and that it was especially true for serum creatinine and urea. Other authors found that ischemic preconditioning decreased renal function or at least had a trend towards it ${ }^{27,28}$.

In short, our study showed that topical hypothermia by itself did not cause histological, oxidative, or functional damage to the kidney. Also, when topical hypothermia was superimposed on ischemia, it had a trend towards preserving renal function and attenuating cell damage, as assessed by $\mathrm{sCr}$ and histological changes, respectively. In contrast, we found that ischemic preconditioning not only lacks protective effects on I/R injury, but rather increases I/R injury.

The major strength of our study is that as far as we are aware, this is the first study to investigate if ischemic preconditioning has synergistic effects with topical hypothermia in decreasing renal I/R injury. Furthermore, there was a clear correlation of ischemic preconditioning with increased I/R injury, as evidenced by higher grades of acute tubular necrosis and higher $\mathrm{sCr}$ at the end of the experiment.

Some potential limitations of our study must be emphasized. First, the acute nature of our experiment, with blood and specimen collection after only $4 \mathrm{~h}$ of reperfusion, could have hindered true (if different) long-term effects of ischemic preconditioning on I/R injury. It is possible that our preconditioning protocol with continuous ischemia for $15 \mathrm{~min}$ was too long, resulting in acute kidney injury per se. However, it is difficult to explain why other groups using similar IPC protocol had opposing results ${ }^{19}$. Second, our protocol was designed to test the "early window of protection", and there is some evidence that the "late window of protection" (ischemic preconditioning $>24$ $\mathrm{h}$ before sustained ischemia) is more efficient in attenuating $I / R$ injury ${ }^{13}$. Third, $I / R$ injury is well-known temperature sensitive. Hence, lower minimum systemic temperature attained in groups subjected to topical hypothermia could affect results ${ }^{29}$. Fourth, there are some data indicating that isoflurane, the volatile anesthetic used, has unique preconditioning characteristics $^{30}$. Hence, it could act as a confounding factor in our outcomes.

\section{Conclusions}

We could not establish additive effects of local ischemic preconditioning and topical hypothermia in protecting the kidney from I/R injury. Moreover, local ischemic preconditioning followed by warm ischemia impaired renal function more than warm ischemia alone.

\section{References}

1. Eltzschig HK, Eckle T. Ischemia and reperfusion--from mechanism to translation. Nat Med. 2011 Nov 7;17(11):1391-401. doi: 10.1038/nm.2507.

2. Kosieradzki M, Rowiński W. Ischemia/ reperfusion injury in kidney transplantation: mechanisms and prevention. Transplant Proc. 2008 Dec 4;40(10):3279-88. doi: 10.1016/j.transproceed.2008.10.004.

3. Sharfuddin AA, Molitoris BA. Pathophysiology of ischemic acute kidney injury. Nat Rev Nephrol. 2011 Apr;7(4):189200. doi: 10.1038/nrneph.2011.16. 
4. Tilney NL, Guttmann RD. Effects of initial ischemia/reperfusion injury on the transplanted kidney. Transplantation. 1997 Oct 15;64(7):945-7. PMID: 9381538.

5. Land WG. The role of postischemic reperfusion injury and other nonantigendependent inflammatory pathways in transplantation. Transplantation. 2005 Mar 15;79(5):505-14. PMID: 15753838.

6. Lu CY, Penfield JG, Kielar ML, Vazquez MA, Jeyarajah DR. Hypothesis: is renal allograft rejection initiated by the response to injury sustained during the transplant process? Kidney Int. 1999 Jun;55(6):2157-68. doi: 10.1046/j.1523-1755.1999.00491.x.

7. Ojo AO, Wolfe RA, Held PJ, Port FK, Schmouder RL. Delayed graft function: risk factors and implications for renal allograft survival. Transplantation. $1997 \mathrm{Apr}$ 15;63(7):968-74. PMID: 9112349.

8. Novick AC. Renal hypothermia: in vivo and ex vivo. Urol Clin North Am. 1983 Nov;10(4):637-44. PMID: 6356550.

9. Becker $F$, van Poppel $H$, Hakenberg OW, Stief C, Gill I, Guazzoni G, Montorsi F, Russo P, Stöckle M. Assessing the impact of ischaemia time during partial nephrectomy. Eur Urol. 2009 Oct;56(4):625-34. doi: 10.1016/j. eururo.2009.07.016.

10.Opelz G, Wujciak T. Comparative analysis of kidney preservation methods. Collaborative Transplant Study. Transplant Proc. 1996 Feb;28(1):87-90. PMID: 8644351.

11. Matas AJ, Smith JM, Skeans MA, Thompson B, Gustafson SK, Schnitzler MA, Stewart DE, Cherikh WS, Wainright JL, Snyder JJ, Israni AK, Kasiske BL. OPTN/SRTR 2012 Annual Data Report: Kidney. Am J Transplant. 2014 Jan 1;14(S1):11-44. doi: 10.1111/ajt.12579.

12. Hausenloy DJ, Yellon DM. Preconditioning and postconditioning: underlying mechanisms and clinical application. Atherosclerosis. 2009 Jun;204(2):334-41. doi: 10.1016/j.atherosclerosis.2008.10.029.

13. Wever KE, Menting TP, Rovers $M$, van der Vliet JA, Rongen GA, Masereeuw R, RitskesHoitinga $M$, Hooijmans $C R$, Warlé $M$. Ischemic preconditioning in the animal kidney, a systematic review and meta-analysis. PLoS ONE. 2012 Feb 28;7(2):e32296. doi: 10.1371/journal.pone.0032296.

14. Hausenloy DJ, Yellon DM. The therapeutic potential of ischemic conditioning: an update.
Nat Rev Cardiol. 2011 Nov;8(11):619-29. doi: $10.1038 /$ nrcardio.2011.85.

15.Das M, Das DK. Molecular mechanism of preconditioning. IUBMB Life. 2008 Apr;60(4):199-203. doi: 10.1002/iub.31.

16.Grezzana Filho Tde J, Mendonça TB, Gabiatti G, Rodrigues G, Marroni NA, Treis L, De Rossi SD, Corso CO. Topical hepatic hypothermia plus ischemic preconditioning: analysis of bile flow and ischemic injuries after initial reperfusion in rats. Acta Cir Bras. 2011;26(3):194-201. PMID: 21537521.

17.Santos EB, Koff WJ, Grezzana Filho Tde J, De Rossi SD, Treis L, Bona SR, Pêgas KL, Katz B, Meyer FS, Marroni NA, Corso CO. Oxidative stress evaluation of ischemia and reperfusion in kidneys under various degrees of hypothermia in rats. Acta Cir Bras. 2013;28(8):568-73. PMID: 23896835.

18.Jablonski P, Howden BO, Rae DA, Birrell CS, Marshall VC, Tange J. An experimental model for assessment of renal recovery from warm ischemia. Transplantation. 1983 Mar;35(3):198-204. PMID: 6340272.

19. Torras J, Herrero-Fresneda I, Lloberas N, Riera M, Ma Cruzado J, Ma Grinyó J. Promising effects of ischemic preconditioning in renal transplantation. Kidney Int. 2002 Jun;61(6):2218-27. doi: 10.1046/j.15231755.2002.00360.x.

20.Johnson KJ, Weinberg JM. Postischemic renal injury due to oxygen radicals. Curr Opin Nephrol Hypertens. 1993 Jul;2(4):62535. PMID: 7859026.

21.Finn WF. Enhanced recovery from postischemic acute renal failure. Micropuncture studies in the rat. Circ Res. L1980 Mar 1;46(3):440-8. PMID: 7357698.

22.Dobashi K, Ghosh B, Orak JK, Singh I, Singh AK. Kidney ischemia-reperfusion: modulation of antioxidant defenses. Mol Cell Biochem. 2000 Feb;205(1-2):1-11. PMID: 10821417.

23.Sela S, Shasha SM, Mashiach E, Haj M, Kristal $B$, Shkolnik T. Effect of oxygen tension on activity of antioxidant enzymes and on renal function of the postischemic reperfused rat kidney. Nephron. 1993;63(2):199-206. PMID: 8450913.

24.Singh I, Gulati S, Orak JK, Singh AK. Expression of antioxidant enzymes in rat kidney during ischemia-reperfusion injury. Mol Cell Biochem. 1993 Aug 25;125(2):97- 
104. PMID: 8283974.

25.Barnard ML, Snyder SJ, Engerson TD, Turrens JF. Antioxidant enzyme status of ischemic and postischemic liver and ischemic kidney in rats. Free Radic Biol Med. 1993 Aug 1;15(2):227-32. PMID: 8375697.

26.Yoshioka T, Bills T, Moore-Jarrett T, Greene $\mathrm{HL}$, Burr IM, Ichikawa I. Role of intrinsic antioxidant enzymes in renal oxidant injury. Kidney Int. 1990 Aug 1;38(2):282-8. PMID: 2402119.

27.Obal D, Dettwiler S, Favoccia C, Rascher K, Preckel B, Schlack W. Effect of sevoflurane preconditioning on ischaemia/reperfusion injury in the rat kidney in vivo. Eur J Anaesthesiol. 2006 Apr;23(4):319-26. doi: $10.1017 / \mathrm{S} 0265021505002000$.

28.Bedir S, Ma Y, Antonelli J, Cadeddu JA, Gahan JC. Ineffectiveness of remote ischemic renal preconditioning in a porcine solitary-kidney model. J Endourol. 2015 May;29(5):590-4. doi: 10.1089/end.2014.0563.
29.Delbridge MS, Shrestha BM, Raftery AT, Nahas EI AM, Haylor JL. The effect of body temperature in a rat model of renal ischemia-reperfusion injury. Transplant Proc. 2007 December;39(10):2983-85. doi: 10.1016/j.transproceed.2007.04.028.

30.Kersten JR, Schmeling TJ, Pagel PS, Gross GJ, Warltier DC. Isoflurane mimics ischemic preconditioning via activation of K(ATP) channels: Reduction of myocardial infarct size with an acute memory phase. Anesthesiology. 1997 Aug 1;87(2):361-70. PMID: 9286901.

\section{Acknowledgements}

The staff of the Animal Experimentation Unit, Protein and Molecular Analysis Unit and Experimental Pathology Unit of the Research Center, HCPA, for their technical assistance and support.

\section{Correspondence:}

Carlos Otávio Corso

Disciplina de Cirurgia Digestiva, HCPA

Rua Ramiro Barcelos, 2350/sala 747

90035-903 Porto Alegre - RS Brasil

Tel.: (55 51)3359-8232

corso@portoweb.com.br

Received: June 27, 2017

Review: Aug 28, 2017

Accepted: Sept 29, 2017
Conflict of interest: none

Financial source: FIPE/HCPA

\begin{abstract}
${ }^{1}$ Research performed at Animal Experimentation Unit, Hospital de Clínicas de Porto Alegre (HCPA), Porto Alegre-RS, Brazil. Part of Master degree thesis, Postgraduate Program in Medicine: Surgical Sciences. Tutor: Carlos Otávio Corso.
\end{abstract}

